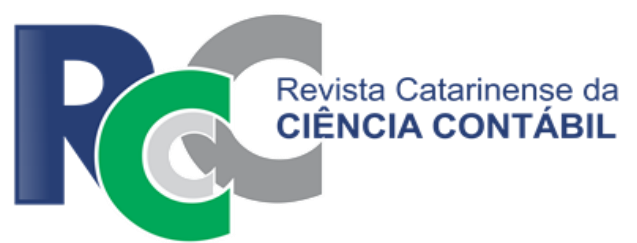

Revista Catarinense da Ciência Contábil,

ISSN 1808-3781 - eISSN 2237-7662.

Florianópolis, SC, v. 16, n. 48, p. 69-85, maio/ago. 2017

\title{
INFLUÊNCIA DOS INVESTIMENTOS AMBIENTAIS E DOS INDICADORES ECONÔMICO-FINANCEIROS NA SELEÇÃO DE EMPRESAS PARA COMPOR O ÍNDICE DE SUSTENTABILIDADE EMPRESARIAL (ISE)*
}

\author{
INFLUENCE OF ENVIRONMENTAL INVESTMENTS AND FINANCIAL \\ PERFORMANCE INDICATORS TO COMPOSE THE CORPORATE SUSTAINABILITY \\ INDEX (ISE)
}

\author{
BÁRBARA BEIRÃO TONOLLI \\ Graduada em Ciências Contábeis pela Universidade Federal de Santa \\ Catarina (UFSC) Endereço: Campus Reitor João David Ferreira \\ Lima, s/n / Trindade / 88040-900 | Florianópolis/SC / Brasil. \\ E-mail: baaaaaah_@hotmail.com

\section{SULIANI ROVER} \\ Pós-doutora em Contabilidade (UFSC). Doutora em Controladoria e \\ Contabilidade (USP). Professora do Departamento de Ciências \\ Contábeis e do Programa de Pós-Graduação em Contabilidade \\ (PPGC) da Universidade Federal de Santa Catarina (UFSC). \\ Endereço: Campus Reitor João David Ferreira Lima, s/n / Trindade / \\ 88040-900 / Florianópolis/SC / Brasil. \\ E-mail: sulianirover@gmail.com
}

\section{DENIZE DEMARCHE MINATTI FERREIRA}

Pós-doutora em Contabilidade. Doutora em Engenharia e Gestão do Conhecimento. Professora do Departamento de Ciências Contábeis da Universidade Federal de Santa Catarina (UFSC). Endereço: Campus Reitor João David Ferreira Lima, s/n / Trindade | 88040-900 | Florianópolis/SC / Brasil.

E-mail: denize.minatti@ufsc.br

\section{RESUMO}

O objetivo geral do trabalho é verificar a influência dos investimentos ambientais e de indicadores econômico-financeiros na seleção das empresas para compor o Índice de Sustentabilidade Empresarial (ISE) no ano de 2014. Com relação à metodologia, esta pesquisa é classificada como descritiva, e, explicativa quanto aos objetivos, com abordagem metodológica quantitativa e qualitativa. A coleta foi realizada por meio de dados secundários e, quanto aos procedimentos, é uma pesquisa documental. A amostra da pesquisa compreende 178 empresas elegíveis ao ISE do período de 2015, ano base 2014. Foram coletados os relatórios de sustentabilidade do ano de 2014 para identificar os investimentos ambientais. Do total de empresas, 95 apresentaram relatórios, sendo que 93 delas divulgaram investimentos ambientais de forma qualitativa e 49, quantitativa. A média dos investimentos ambientais totalizou $\mathrm{R} \$ 158.028 .447,36$. A técnica estatística utilizada para verificar que variáveis influenciam na seleção de empresas para compor o ISE foi a regressão logística, tendo como variáveis explicativas: ativo total, rentabilidade do ativo, liquidez corrente, grau de endividamento, Novo Mercado, investimentos ambientais de forma qualitativa e quantitativa.

\footnotetext{
* Trabalho que obteve $3^{a}$ colocação no Prêmio Excelência Acadêmica, Fundação Instituto Capixaba de Pesquisas em Contabilidade, Economia e Finanças - FUCAPE (2016).

Submissão em 05/07/2016. Revisão em 26/09/2016. Aceito em 05/05/2017.
} 
Pela análise dos resultados, concluiu-se que tamanho, rentabilidade do ativo, grau de endividamento e investimento ambiental quantitativo influenciam as companhias a serem selecionadas para compor o ISE. A variável tamanho foi significativa ao nível de $1 \%$, grau de endividamento e investimentos ambientais quantitativos ao nível de $5 \%$ e rentabilidade ao nível de $10 \%$.

Palavras chave: Índice de Sustentabilidade Empresarial (ISE). Indicadores econômicofinanceiros. Investimentos ambientais.

\begin{abstract}
This study aims to investigate the influence of environmental investments and financial performance indicators in 2014's Corporate Sustainability Index (ISE). This research is classified as descriptive, with a quantitative and qualitative approach. It is a documentary research, based on procedures and sourced by secondary data. The research sample comprises 178 companies eligible to ISE in 2015, base year 2014. The 2014 Sustainability Reports are referenced in order to identify environmental investments. Of the 178 companies, 95 published sustainability reports, of which 93 reported environmental investments qualitatively and 49 , quantitative. On average, environmental investments totaled $R \$ 158,028,447,36$. The statistical technique used to determine which variables influenced entry to ISE was regression. Total assets, asset profitability, current liquidity, indebtedness, Novo Mercado, qualitative and quantitative environmental investments were used as independent variables. In conclusion, asset profitability, indebtedness and quantitative environmental investments influence companies for selection to compose ISE. The company size was calculated to have $1 \%$ level of significance, indebtedness and quantitative environmental investments $5 \%$ and, profitability $10 \%$.
\end{abstract}

Keywords: Corporate Sustainability Index (ISE). Financial Performance Indicators. Environmental Investments.

\title{
1 INTRODUÇÃO
}

A sociedade vem refletindo cada vez mais sobre o meio ambiente, por ser fundamental para a qualidade de vida. Devido a essa preocupação, os consumidores prezam por posturas ambientalmente corretas adotadas por algumas empresas, já que assim é possível minimizar impactos ambientais por elas gerados.

O desenvolvimento sustentável ameniza a agressão ao meio ambiente. A definição de desenvolvimento sustentável surgiu no relatório Brundtland ao conceituar como "aquele que atende às necessidades do presente sem comprometer a possibilidade de as gerações futuras atenderem a suas próprias necessidades" (Comissão Mundial sobre o Meio Ambiente e Desenvolvimento, 1991, p. 46).

Deste então, diante das pressões da sociedade para com as empresas, o processo de divulgação tornou-se mais eficiente. O disclosure ambiental é entendido como o ato de divulgar ou evidenciar práticas relacionadas ao meio ambiente, um adequado mecanismo de transparência das companhias.

O ISE foi criado em 2005 pela Bolsa de Valores de São Paulo (BOVESPA). É o primeiro indicador de sustentabilidade da América Latina e o quarto desse tipo no mundo (Favaro \& Rover, 2014), "com o objetivo de mostrar o desempenho de mercado de uma carteira formada por empresas que adotam os princípios de gestão sustentável" (Marcondes \& Bacarji, 2010, p.18). Para participar do ISE a empresa deve possuir uma das 200 ações mais líquidas da BMF\&Bovespa. O índice é composto por até 40 dessas empresas. O intuito é agregar empresas com foco em sustentabilidade, baseada em princípios de eficiência econômica, equilíbrio socioambiental e governança corporativa (BMF\&Bovespa, 2015).

De acordo com Dalmácio e Paulo (2004, p.7), "as empresas possuem um compromisso social com a sociedade, não devendo mais almejar somente o lucro". Ressaltam que é necessária a preservação do meio ambiente, pois as companhias são peças relevantes para o 
desenvolvimento econômico e social do país. Desenvolver produtos sustentáveis pode significar melhores retornos financeiros e econômicos para as empresas, fortalecendo a marca e a imagem (Pereira, Silva, \& Carbonari, 2011). Mas, de acordo com Barbieri (2011), para grande parte das empresas essa preocupação ainda não é efetiva, pois se realmente fosse, o acúmulo de problemas ambientais não seria tão intenso.

Pela importância do desenvolvimento sustentável, da responsabilidade social, da transparência e da governança corporativa é fundamental que as empresas façam investimentos ambientais. Com base no exposto, questiona-se: Qual a influência dos investimentos ambientais e indicadores econômico-financeiros na seleção de empresas para compor o ISE? Para responder a esse questionamento, o objetivo do estudo é verificar a influência dos investimentos ambientais e indicadores econômico-financeiros na seleção de empresas para compor o ISE.

Assim, esta pesquisa justifica-se pela importância de se investigar se empresas maiores, mais rentáveis, com alta liquidez, menor endividamento, integrantes do novo mercado e com investimentos ambientais possuem maior probabilidade de pertencer ao ISE.

\section{REVISÃO DA LITERATURA}

Empresas evidenciam as questões ambientais por meio do balanço social ou no relatório da administração, além da divulgação em relatórios ambientais (Tinoco \& Kraemer, 2011). Segundo Barbieri (2011, p. 279), "o balanço social é um instrumento para tornar transparente a responsabilidade social da empresa", e conforme Tinoco e Kraemer (2011, p.235), "são os meios que empresas adotam para descrever e divulgar seu desempenho ambiental".

Dias (2012, p.144) explica que os relatórios "constituem uma forma de accountability, baseado no conceito de triple bottom line" e que a elaboração abrange a medição, divulgação e prestação de contas, fundamentando-se em uma informação de responsabilidade social, permitindo a repercussão socioambiental da atuação da empresa.

A comunicação do desempenho socioambiental é importante. Contribui para a prestação de contas e transparência (Dias, 2012). Vellani (2011, p.39) afirma que "transparência, no contexto dos negócios, significa a empresa permitir o acesso à realidade por meio dos relatórios contábeis". Para Tachizawa (2015) a implementação do balanço social é focada na responsabilidade pública e transparência das companhias.

O Global Reporting Initiative (GRI) é uma organização internacional independente criada no final dos anos 1990 que tem por objetivo auxiliar as empresas, governos e outras organizações a compreender e comunicar o impacto sobre questões de sustentabilidade, tais como alterações climáticas, direitos humanos, corrupção e outras (GRI, 2016).

O GRI atua de forma transparente e responsável, com o objetivo de obter uma economia sustentável, em que as empresas possam medir desempenhos sociais, econômicos e ambientais (GRI, 2012). As diretrizes GRI trazem informações adequadas e atualizadas, ajudando a tornar a divulgação de questões sustentáveis uma prática entre empresas (GRI, 2013). O GRI surge para "tornar os relatórios de sustentabilidade tão comuns quanto os relatórios financeiros" (GRI, 2012, p.16). Bronstein (2015) afirma que o cenário mudou a partir de 2006 com o lançamento da G3 em português. O G4 é o modelo atual do GRI, porém algumas empresas ainda utilizam o G3.

Em 1999 foi criado em Nova York o primeiro índice que considera aspectos sustentáveis, o Dow Jones Sustainability Indexes, e, em seguida (2001), o FTSE4Good, de Londres. O terceiro é de Joanesburgo, JSE de 2003 e, em 2005, surge no Brasil o ISE (Favaro \& Rover, 2014).

Conforme Barbieri e Cajazeira (2009), o ISE integra as empresas que se destacam nas três dimensões da sustentabilidade e em governança, formando uma carteira de ações que represente o benchmark brasileiro. Essas iniciativas buscam criar referências com base na definição de empresa sustentável, mediante um sistema de gestão relacionado à política de responsabilidade social. Teixeira, Nossa e Funchal (2011) e Pereira et al. (2011) corroboram o conceito anterior ao definirem o objetivo do índice de ser um benchmark de organizações que 
proporcionem boas práticas sustentáveis comprometendo-se com a responsabilidade social corporativa e a sustentabilidade empresarial.

Marcondes e Bacarji (2010) afirmam que o ISE torna o mercado mais atrativo para investidores, especialmente os comprometidos com investimentos socialmente responsáveis, pois incentiva empresas a introduzir questões sociais, ambientais e de governança na tomada de decisão sobre os investimentos. Logo, a missão do ISE é fazer com que as empresas adotem práticas ambientais, auxiliando os investidores nas decisões referentes a investimentos sustentáveis (ISE, 2015).

Os indicadores ambientais, conforme França (2004), apresentam os resultados referentes ao desempenho ambiental e são importantes instrumentos de medida que permitem melhorias no âmbito da sustentabilidade, por meio da implementação de ações. Azevedo (2006) destaca que os indicadores devem ser adequados para que seja possível avaliar as práticas da empresa com relação ao desenvolvimento sustentável. Vellani (2011) define os indicadores ambientais físicos e monetários como sendo o principal instrumento das empresas para avaliar a sustentabilidade. Promovem informações relevantes para os tomadores de decisão.

O ISE é fundamental no âmbito sustentável. Identifica as empresas que se preocupam com a governança por meio de um sistema de gestão ambiental relacionado à responsabilidade social. Faz com que os pesquisadores comecem a centrar seus estudos na área (Tabela 1).

\section{Tabela 1}

\section{Estudos anteriores}

\begin{tabular}{|c|c|}
\hline Autor (es) /ano & Estudo \\
\hline $\begin{array}{l}\text { Bertagnolli, Ott e Damacena } \\
\qquad(2006)\end{array}$ & $\begin{array}{l}\text { Os autores determinaram a influência dos investimentos socioambientais no } \\
\text { desempenho econômico das empresas. Utilizaram balanços sociais de } 176 \\
\text { empresas (IBASE) e indicadores sociais internos e externos e indicadores } \\
\text { ambientais (variáveis independentes) e a receita líquida e resultado } \\
\text { operacional (variáveis dependentes) e constataram que os investimentos } \\
\text { explicam alterações nas variáveis dependentes. }\end{array}$ \\
\hline $\begin{array}{l}\text { Macedo, Souza, Souza e Cipola, } \\
(2007)\end{array}$ & $\begin{array}{l}\text { Os pesquisadores avaliaram a performance das empresas do ISE por meio } \\
\text { de indicadores de liquidez, endividamento e lucratividade entre empresas da } \\
\text { Revista Melhores e Maiores e compararam as que pertencem ao ISE com as } \\
\text { demais. Os autores concluíram não haver vantagens significativas das } \\
\text { empresas socialmente responsáveis sobre o mercado. }\end{array}$ \\
\hline $\begin{array}{l}\text { Ott, Alves e Flores } \\
\text { (2009) }\end{array}$ & $\begin{array}{l}\text { Os autores replicaram a metodologia de Bertagnolli et al. (2006) e } \\
\text { analisaram investimentos ambientais e desempenho econômico das } \\
\text { empresas com uma amostra composta por } 353 \text { companhias, e apresentaram } \\
\text { resultados semelhantes ao da pesquisa de } 2006 \text {. }\end{array}$ \\
\hline $\begin{array}{l}\text { Nunes } \\
(2010)\end{array}$ & $\begin{array}{l}\text { Foram analisadas as variáveis (tamanho, setor de atividade, concentração } \\
\text { acionária, localização do controle acionário, ser emissora de ADR e ser de } \\
\text { propriedade estatal) de } 124 \text { empresas que levaram a adesão ao ISE. } \\
\text { Concluíram que o tamanho da empresa e setor de atividade interferiram na } \\
\text { entrada ao ISE. }\end{array}$ \\
\hline $\begin{array}{l}\text { Guimarães } \\
(2010)\end{array}$ & $\begin{array}{l}\text { O autor avaliou se a passagem das companhias pelo ISE influencia o valor } \\
\text { da empresa a longo prazo. Os resultados não confirmaram o aumento do } \\
\text { valor das empresas. }\end{array}$ \\
\hline $\begin{array}{c}\text { Machado, Macedo, Machado e } \\
\text { Siqueira } \\
\text { (2012) }\end{array}$ & $\begin{array}{l}\text { Investigaram a relação entre investimentos socioambientais e a inclusão de } \\
\text { empresa ao ISE por meio de regressão logística e, concluíram que houve } \\
\text { relação positiva entre eles, demonstrando comprometimento da empresa } \\
\text { com a sustentabilidade. }\end{array}$ \\
\hline $\begin{array}{c}\text { Garcia e Orsato } \\
(2013)\end{array}$ & $\begin{array}{l}\text { Pesquisaram } 15 \text { trabalhos acadêmicos com diversos métodos de avaliação } \\
\text { econômico-financeira ente } 2006 \text { e } 2011 \text {, verificando a criação de valor para } \\
\text { as empresas que compuseram o ISE. Os autores não encontraram } \\
\text { diferenças expressivas entre o fato da empresa aderir ao índice e o impacto } \\
\text { no valor de suas ações. }\end{array}$ \\
\hline
\end{tabular}

Nota. Fonte: Elaborada pelas autoras (2015)

No estudo de Bertagnolli et al. (2006) e Ott et al. (2009) os investimentos ambientais interferiram no desempenho econômico das empresas. Para Machado et al. (2012) houve relação positiva entre os investimentos e a adesão das empresas ao ISE. Segundo Nunes, Teixeira, Nossa e Galdi (2010) alguns fatores interferiram no ingresso de companhias ao ISE. 
De acordo com Macedo et al. (2007), Nunes (2010), Guimarães (2010), Garcia e Orsato (2013), não houve diferenças significativas de empresas socialmente responsáveis sobre as demais. Logo, por meio dos estudos anteriores, percebeu-se que dependendo da análise os investimentos ambientais podem influenciar ou não na adesão das companhias.

\section{METODOLOGIA}

Este trabalho classifica-se em descritivo, e explicativo, pois os resultados obtidos indicam quais variáveis explicam a seleção das empresas para compor o ISE. Com relação à abordagem metodológica, a pesquisa é predominantemente quantitativa, uma vez que foram realizados testes estatísticos por meio da regressão logística e, também, qualitativa, quando se verificou a divulgação de investimentos ambientais.

A fonte de coleta deu-se por meio de dados secundários. Segundo Loesch $(2012$, p.3) são "publicados ou comunicados por outro pesquisador ou outra organização" e utilizada a análise de conteúdo. A busca dos valores dos investimentos ambientais consistiu em "um método de análise de dados que pode ser aplicado tanto para estudos qualitativos como nas investigações quantitativas" (Beuren, 2006, p.137). Para a coleta de dados verificaram-se os aspectos ambientais nos relatórios de sustentabilidade das empresas que compõem as ações mais líquidas no ano de 2014, conforme o website da BMF\&Bovespa. Por meio desses relatórios buscou-se no modelo índice remissivo GRI, o item EN31(G4) ou EN30 (G3) "total de investimentos e gastos com proteção ambiental". Com relação às empresas que não apresentavam esse tópico, o valor foi obtido pelo balanço social, modelo IBASE. Quando a empresa retratou o valor quantitativo no GRI: tabela, textos e balanço social, priorizou-se a tabela quando apresentava o total do investimento.

Se a empresa não evidenciou o balanço social e o GRI, coletou-se os dados referentes ao meio ambiente em tópicos como: Desempenho ambiental, Gestão socioambiental, Ambiental e Capital natural. Além disso, para busca da informação quantitativa foi pesquisado por R\$ e "invest".

Para a amostra selecionaram-se as 200 ações mais líquidas da BMF\&Bovespa de 2014. O ISE é composto por até 40 dessas empresas. Algumas empresas apresentaram dois tipos de ações, como ordinárias e preferenciais, portanto, restaram 182 companhias. A Tabela 2 traz a quantidade de empresas elegíveis ao ISE e exclusões realizadas.

Tabela 2

\section{Quantidade de empresas elegíveis analisadas}

\begin{tabular}{lc}
\hline Total de empresas elegíveis ao ISE & 182 \\
\hline (-) Anhanguera (fusão com a Kroton) & 1 \\
(-) Auto Metal (informações não disponíveis) & 1 \\
(-) BHG (processo de fechamento de capital) & 1 \\
(-) Sierra Brasil (não possui o relatório em português) & 1 \\
\hline Total de empresas analisadas & $\mathbf{1 7 8}$ \\
\hline
\end{tabular}

Nota. Fonte: Dados da Pesquisa (2015).

Foram excluídas a Auto Metal por não estar listada na BMF\&Bovespa, a BHG, que se encontra em processo de fechamento de capital e a Anhanguera pois fez fusão com a Kroton. Algumas empresas mudaram de nome, outras se fundiram ou foram incorporadas. Como exemplo a IMC Holdings é considerada como IMC S/A, pois foi incorporada. E a LLX LOG passou a se chamar Prumo Logística S.A.

Em relação às empresas possuírem ou não relatório, a Ideiasnet apesar de possuir relatório anual, foi desconsiderada por não estar enquadrada nos moldes, uma vez que não apresentou aspectos sociais e/ou ambientais. Da mesma forma a Cetip, apesar de apresentar questões sociais, não mencionou as ambientais, portanto, foi considerado que a empresa não possuía relatório de sustentabilidade.

A Cosan, mesmo não tendo tópico específico sobre o meio ambiente em seu relatório, por meio das palavras-chave, foram encontrados dados que possibilitaram afirmar que a empresa possui investimentos ambientais de forma qualitativa, como: projetos relativos à identificação de riscos socioambientais nos negócios, processo ecoeficiente de destinação 
final das sobras de materiais utilizados e investimento em gestão eficiente e responsável da terra. A Tupy também não apresentou tópico relacionado ao aspecto ambiental, mas ao pesquisar pelas palavras-chave foi encontrada apenas a informação quantitativa.

Foi realizado contato via e-mail com Sulamerica, Sierrabrasil e Lojas Americanas. Com relação à Sulamerica foram solicitadas informações referentes a um relatório escrito, pois só havia disponibilizado em vídeo. Como resposta, a empresa afirmou que apenas possui a versão em vídeo, portanto, foi analisado somente o aspecto relacionado à sustentabilidade. Já a Sierrabrasil foi excluída, por não apresentar o relatório completo em português, não se obtendo resposta. Do e-mail solicitando o relatório completo enviado a Lojas Americanas e também não se obteve resposta. Foi utilizado apenas o resumido no website da Companhia Verde, pois o link do relatório na íntegra acusava erro.

Os índices foram coletados na base de dados do Software Economática, utilizando as informações consolidadas de 2014 das empresas para os cálculos e optou-se por utilizar: ativo total (TAM), rentabilidade do ativo (ROA), liquidez corrente (LIQC) e grau de endividamento (GEND). Para a análise da influência dos investimentos ambientais coletou-se a lista que apresenta as empresas que compõem a carteira de 2015 e comparou-se com as empresas elegíveis de 2015, no ano base 2014 que são informadas no website da BMF\&Bovespa, e utilizou-se a técnica de análise estatística de regressão logística (Fávero, Belfiore, Silva, \& Chan, 2009) para verificar se os fatores como: ativo total, rentabilidade do ativo, liquidez corrente, grau de endividamento, novo mercado e investimentos ambientais explicam a seleção das empresas para compor o ISE.

\section{RESULTADOS}

As empresas do ISE se destacam no setor de Utilidade Pública, representando $27,5 \%$, especificamente o segmento de Energia Elétrica com 11 companhias. Para as empresas não pertencentes ao ISE os dois setores de maior representatividade são: Construção e Transporte e Consumo Cíclico correspondendo a 18,84\% cada. O segmento de Construção e Engenharia representa $69,23 \%$ do total do setor, é o que possui mais companhias. O setor de Utilidade Pública não é muito representativo. É equivalente a $7,97 \%$ das empresas não pertencentes ao ISE (Tabela 3).

Tabela 3

Quantidade de empresas elegíveis por setor e segmento

\begin{tabular}{|c|c|c|c|c|c|}
\hline Setor & Segmento & ISE & $\begin{array}{c}\text { \% ISE } \\
\text { por setor }\end{array}$ & Não ISE & $\begin{array}{l}\text { \% Não ISE } \\
\text { por setor }\end{array}$ \\
\hline \multirow{3}{*}{ Bens industriais } & Máquinas e Equipamentos & 1 & \multirow{3}{*}{$5,00 \%$} & 4 & \multirow{3}{*}{$8,70 \%$} \\
\hline & Material de Transporte & 1 & & 5 & \\
\hline & Serviços & 0 & & 3 & \\
\hline \multirow{2}{*}{$\begin{array}{c}\text { Construção e } \\
\text { transporte }\end{array}$} & Construção e engenharia & 1 & \multirow{2}{*}{$10,00 \%$} & 18 & \multirow{2}{*}{$18,84 \%$} \\
\hline & Transporte & 3 & & 8 & \\
\hline \multirow{7}{*}{ Consumo cíclico } & Comércio & 3 & \multirow{7}{*}{$7,50 \%$} & 6 & \multirow{7}{*}{$18,84 \%$} \\
\hline & Diversos & 0 & & 8 & \\
\hline & Hotéis e Restaurantes & 0 & & 1 & \\
\hline & Mídia & 0 & & 2 & \\
\hline & Tecido, Vestuário e Calçados & 0 & & 5 & \\
\hline & Utilidades Domésticas & 0 & & 2 & \\
\hline & Viagens e Lazer & 0 & & 2 & \\
\hline \multirow{8}{*}{ Consumo não cíclico } & Agropecuária & 0 & \multirow{8}{*}{$7,50 \%$} & 2 & \multirow{8}{*}{$15,22 \%$} \\
\hline & Alimentos processados & 1 & & 8 & \\
\hline & Bebidas & 0 & & 1 & \\
\hline & Comércio e Distribuição & 0 & & 4 & \\
\hline & Diversos & 0 & & 1 & \\
\hline & Fumo & 0 & & 1 & \\
\hline & Produtos de Uso Pessoal e de Limpeza & 1 & & 0 & \\
\hline & Saúde & 1 & & 4 & \\
\hline
\end{tabular}


Tabela 3 (continuação)

\begin{tabular}{|c|c|c|c|c|c|}
\hline Setor & Segmento & ISE & $\begin{array}{c}\% \text { ISE } \\
\text { por setor }\end{array}$ & Não ISE & $\begin{array}{l}\text { \% Não ISE } \\
\text { por setor }\end{array}$ \\
\hline \multirow{5}{*}{ Financeiro e outros } & Exploração de imóveis & 0 & \multirow{5}{*}{$20,00 \%$} & 9 & \multirow{5}{*}{$16,67 \%$} \\
\hline & Holdings Diversificadas & 0 & & 2 & \\
\hline & Intermediários financeiros & 6 & & 6 & \\
\hline & Previdência e Seguros & 1 & & 3 & \\
\hline & Serviços Financeiros Diversos & 1 & & 3 & \\
\hline \multirow{5}{*}{ Materiais básicos } & Madeira e Papel & 3 & \multirow{5}{*}{$17,50 \%$} & 2 & \multirow{5}{*}{$7,25 \%$} \\
\hline & Materiais Diversos & 0 & & 2 & \\
\hline & Mineração & 1 & & 1 & \\
\hline & Químicos & 1 & & 1 & \\
\hline & Siderurgia e Metalurgia & 2 & & 4 & \\
\hline $\begin{array}{c}\text { Petróleo, gás e } \\
\text { biocombustíveis }\end{array}$ & Petróleo, Gás e Biocombustíveis & 0 & $0 \%$ & 2 & $1,45 \%$ \\
\hline \multirow{2}{*}{$\begin{array}{l}\text { Tecnologia da } \\
\text { informação }\end{array}$} & Computadores e equipamentos & 0 & \multirow{2}{*}{$0 \%$} & 2 & \multirow{2}{*}{$4,35 \%$} \\
\hline & Programas e serviços & 0 & & 4 & \\
\hline \multirow{2}{*}{ Telecomunicações } & Telefonia Fixa & 1 & \multirow{2}{*}{$5,00 \%$} & 1 & \multirow{2}{*}{$0,72 \%$} \\
\hline & Telefonia Móvel & 1 & & 0 & \\
\hline \multirow{3}{*}{ Utilidade pública } & Água e saneamento & 1 & \multirow{3}{*}{$27,50 \%$} & 2 & \multirow{3}{*}{$7,97 \%$} \\
\hline & Energia elétrica & 10 & & 8 & \\
\hline & Gás & 0 & & 1 & \\
\hline & Total & 40 & $100,00 \%$ & 138 & $100,00 \%$ \\
\hline
\end{tabular}

Nota. Fonte: Dados da Pesquisa (2015).

A categorização das empresas elegíveis por segmento foi realizada conforme os níveis de governança corporativa da BMF\&Bovespa: Nível 1, Nível 2 e Novo Mercado, e as do mercado tradicional foram incluídas para englobar as empresas que negociam ações na bolsa, mas não estão listadas nos níveis de governança corporativa. Verifica-se, assim como as empresas do ISE, as empresas não pertencentes ao ISE representam maior número do que as pertencentes ao Novo Mercado e possuem maior porcentagem, representando $68,84 \%$ contra $52,5 \%$ das pertencentes ao ISE (Tabela 4 ).

Tabela 4

Quantidade de empresas elegíveis por tipo de mercado

\begin{tabular}{cccc}
\hline Tipo de Mercado & ISE & NÃO ISE & Total das empresas \\
\hline Nível 1 & 11 & 15 & 26 \\
Nível 2 & 3 & 14 & 17 \\
Novo Mercado & 21 & 95 & 116 \\
Tradicional & 5 & 14 & 19 \\
\hline Total & $\mathbf{4 0}$ & $\mathbf{1 3 8}$ & $\mathbf{1 7 8}$
\end{tabular}

Nota. Fonte: Dados da Pesquisa (2015).

Na Tabela 5 é apresentada a quantidade de empresas elegíveis ao ISE que possuem relatório de sustentabilidade em $2014,53,37 \%$ das quais publicaram tais documentos. Todas as empresas ISE divulgaram os relatórios em 2014, já as não ISE aproximadamente $40 \%$, 0 que permite identificar que todas as empresas ISE e $40 \%$ das não pertencentes ao ISE mencionaram informações ambientais em seus relatórios de sustentabilidade.

Tabela 5

Quantidade de empresas elegíveis que divulgaram relatório de sustentabilidade em 2014

\begin{tabular}{cccc} 
Empresas Elegíveis & Total de empresas & Total de relatórios 2014 & $\begin{array}{c}\text { \% de empresas que possui } \\
\text { relatório }\end{array}$ \\
\hline ISE & 40 & 40 & $100,00 \%$ \\
NÃO ISE & 138 & 55 & $39,86 \%$ \\
\hline Total & $\mathbf{1 7 8}$ & $\mathbf{9 5}$ & $\mathbf{5 3 , 3 7 \%}$ \\
\hline
\end{tabular}

Nota. Fonte: Dados da Pesquisa (2015).

Como todas as empresas do ISE divulgaram relatórios e o setor de Utilidade Pública é predominante, consequentemente é o que apresentou a maior quantidade de documentos. Os setores que contêm mais empresas não pertencentes ao ISE são: Construção e Transporte e 
Consumo Cíclico representando 18,84\%. Em terceiro lugar é o Financeiro e Outros com $16,67 \%$. O setor que divulgou mais relatórios é o de Consumo não Cíclico, seguido por Construção e Transporte e Financeiro e Outros. Percebe-se que as empresas não pertencentes ao ISE, apesar de serem as em maior número, não são as que mais apresentaram relatórios, como é o caso do setor de Consumo Cíclico (Tabela 6).

Tabela 6

Quantidade de empresas elegíveis que divulgaram relatórios por setor

\begin{tabular}{ccc}
\hline Setor & Quantidade de relatórios - ISE & Quantidade de relatórios - não ISE \\
\hline Bens industriais & 2 & 5 \\
Construção e transporte & 4 & 9 \\
Consumo cíclico & 3 & 7 \\
Consumo não cíclico & 3 & 10 \\
Financeiro e outros & 8 & 9 \\
Materiais básicos & 7 & 3 \\
Petróleo, gás e biocombustíveis & 0 & 2 \\
Tecnologia da informação & 0 & 2 \\
Telecomunicações & 2 & 1 \\
Utilidade pública & 11 & 7 \\
\hline Total & $\mathbf{4 0}$ & $\mathbf{5 5}$
\end{tabular}

Nota. Fonte: Dados da Pesquisa (2015)

Os dados expostos na Tabela 7 revelam que grande parte das empresas divulgou o relatório anual, seguido pelo relatório de sustentabilidade. As empresas não pertencentes ao ISE apresentaram relatórios menos padronizados se comparadas às empresas do ISE, pois utilizaram outras nomenclaturas, como: performance, balanço socioambiental, balanço social, relatório socioambiental e relatório anual de responsabilidade socioambiental.

Tabela 7

Tipo de relatório

\begin{tabular}{lccc}
\hline Tipo de relatório 2014 & ISE & NÃO ISE & Total das empresas \\
\hline Relatório anual & 14 & 23 & 37 \\
Relatório de sustentabilidade & 11 & 18 & 29 \\
Relatório anual e de sustentabilidade & 9 & 6 & 15 \\
Relatório anual de sustentabilidade & 3 & 2 & 5 \\
Relatório anual integrado & 2 & - & 1 \\
Relato integrado anual & 1 & - & 2 \\
Performance & - & 2 & 1 \\
Balanço socioambiental & - & 1 & 1 \\
Balanço social & - & 1 & 1 \\
Relatório anual de responsabilidade socioambiental & - & 1 & 1 \\
Relatório socioambiental & - & 1 & $\mathbf{9 5}$
\end{tabular}

Nota. Fonte: Dados da Pesquisa (2015).

Conforme Tabela 8, das 40 empresas do ISE que divulgaram relatório em 2014, 36 apresentaram o índice remissivo GRI. 6 mencionaram o G3 e 30, o G4. Foram utilizadas 4 empresas que divulgaram o $\mathrm{G} 3 \mathrm{e}, 20$, o G4, para mencionar o valor quantitativo das empresas com base na informação "total de investimentos e gastos com proteção ambiental".

Tabela 8

Quantidade de empresas elegíveis que divulgaram relatório no modelo GRI

\begin{tabular}{ccccc}
\hline Empresas elegíveis & $\begin{array}{c}\text { Total de relatórios } \\
\mathbf{2 0 1 4}\end{array}$ & $\begin{array}{c}\text { Total de empresas que } \\
\text { apresentam GRI }\end{array}$ & GRI G3 & GRI G4 \\
\hline ISE & 40 & 36 & 6 & 30 \\
NÃO ISE & 55 & 30 & 6 & 24 \\
\hline Total & $\mathbf{9 5}$ & $\mathbf{6 6}$ & $\mathbf{1 2}$ & $\mathbf{5 4}$ \\
\hline
\end{tabular}

Nota. Fonte: Dados da Pesquisa (2015).

Das 55 empresas não pertencentes ao ISE, que divulgaram relatório em 2014, 30 divulgaram o GRI. 6 possuem o G3 e 24, o G4. Somente 4 empresas, o G3 e, 12, o G4, 
informaram o valor quantitativo no tópico "total de investimentos e gastos com proteção ambiental".

Para as empresas que não possuíam o GRI, buscou-se a informação no balanço social. A Ultrapar foi a única que mencionou valores quantitativos no balanço social. Para as demais foi pesquisado no tópico relacionado ao meio ambiente, buscando algum valor monetário. Constatou-se que $90 \%$ das empresas ISE apresentaram algum modelo GRI, e $54,54 \%$ das empresas não ISE divulgaram o modelo G3 ou G4, o que aparentemente demonstra que as empresas ISE procuram dar maior acessibilidade às informações. Das empresas elegíveis aproximadamente $70 \%$ divulgaram algum modelo GRI, $81,82 \%$ por meio do GRI G4.

A Tabela 9 apresenta a quantidade de empresas elegíveis que divulgaram investimentos ambientais de forma qualitativa e/ou quantitativa.

Tabela 9

\section{Empresas elegíveis que divulgaram investimentos ambientais de forma qualitativa e/ou} quantitativa

\begin{tabular}{cccc}
\hline Empresas Elegíveis & Total de relatórios 2014 & \multicolumn{2}{c}{ Investimentos ambientais } \\
Qualitativos & 27 \\
\hline ISE & 40 & 40 & 22 \\
NÃO ISE & 55 & 53 & $\mathbf{4 9}$ \\
\hline Total & 95 & 93 & 93 \\
\hline
\end{tabular}

Nota. Fonte: Dados da Pesquisa (2015).

Todas as empresas do ISE divulgaram investimentos ambientais de forma qualitativa. $67,5 \%$ também divulgaram valores quantitativos. Já, das não pertencentes ao ISE, somente a Multiplus e Tupy não mencionaram os investimentos de forma qualitativa em seu relatório anual e de sustentabilidade e $40 \%$ das empresas divulgaram valores quantitativos. Do total das empresas elegíveis, que divulgaram relatórios, $97,89 \%$ mencionaram os investimentos ambientais de forma qualitativa e somente $51,58 \%$ divulgaram investimentos ambientais quantitativos.

Por meio dos dados expostos na Tabela 10, constata-se que o setor das empresas do ISE que mais divulgou investimentos ambientais de forma qualitativa é o de Utilidade Pública. Já das empresas não pertencentes ao ISE é o setor de Consumo não Cíclico, representado por 10 empresas. O setor de empresas elegíveis que mais mencionou os investimentos ambientais de forma qualitativa foi o de Utilidade Pública, seguido pelo Financeiro e Outros.

Tabela 10

Empresas elegíveis que divulgaram investimentos ambientais de forma qualitativa por setor

\begin{tabular}{|c|c|c|c|c|c|}
\hline Setor & $\begin{array}{c}\text { Investimentos } \\
\text { ambientais de } \\
\text { forma } \\
\text { qualitativa - } \\
\text { ISE }\end{array}$ & $\begin{array}{c}\% \\
\text { Investimentos } \\
\text { ambientais de } \\
\text { forma } \\
\text { qualitativa - } \\
\text { ISE }\end{array}$ & $\begin{array}{c}\text { Investimentos } \\
\text { ambientais de } \\
\text { forma } \\
\text { qualitativa - } \\
\text { Não ISE }\end{array}$ & $\begin{array}{c}\% \\
\text { Investimentos } \\
\text { ambientais de } \\
\text { forma } \\
\text { qualitativa - } \\
\text { Não ISE }\end{array}$ & $\begin{array}{c}\text { Total } \\
\text { Investimentos } \\
\text { ambientais de } \\
\text { forma } \\
\text { qualitativa }\end{array}$ \\
\hline Bens industriais & 2 & 5,00 & 3 & 5,66 & 5 \\
\hline Construção e transporte & 4 & 10,00 & 9 & 16,98 & 13 \\
\hline Consumo cíclico & 3 & 7,50 & 7 & 13,21 & 10 \\
\hline Consumo não cíclico & 3 & 7,50 & 10 & 18,87 & 13 \\
\hline Financeiro e outros & 8 & 20,00 & 9 & 16,98 & 17 \\
\hline $\begin{array}{l}\text { Materiais básicos } \\
\text { Petróleo, gás e }\end{array}$ & 7 & 17,50 & 3 & 5,66 & 10 \\
\hline $\begin{array}{l}\text { biocombustíveis } \\
\text { Tecnologia da }\end{array}$ & 0 & 0,00 & 2 & 3,77 & 2 \\
\hline informação & 0 & 0,00 & 2 & 3,77 & 2 \\
\hline Telecomunicações & 2 & 5,00 & 1 & 1,89 & 3 \\
\hline Utilidade pública & 11 & 27,50 & 7 & 13,21 & 18 \\
\hline Total & 40 & 100,00 & 53 & 100,00 & 93 \\
\hline
\end{tabular}

Nota. Fonte: Dados da Pesquisa (2015) 
Todas as empresas do ISE pertencentes ao setor de Utilidade Pública mencionaram investimentos ambientais de forma qualitativa. É esse o setor de maior representatividade correspondendo a $40,74 \%$.

Das empresas não participantes no ISE os setores de Construção e Transporte e o de Utilidade Pública são o que mais se destacaram, correspondendo a $22,73 \%$ cada. Essa análise indica que apesar de o setor de Consumo não Cíclico possuir mais empresas com divulgação de investimentos ambientais de forma qualitativa, não é o que possui maior número de empresas com divulgação de investimentos quantitativos. Apenas 3 das 10 empresas mencionaram os investimentos de forma qualitativa, conforme Tabela 11. Os setores de Construção e Transporte e Utilidade Pública indicados na Tabela 10, com 9 e 7 empresas, respectivamente, possuem 5 empresas que divulgaram investimentos quantitativos.

Tabela 11

Empresas elegíveis que divulgaram investimentos ambientais quantitativos por setor

\begin{tabular}{|c|c|c|c|c|c|}
\hline Setor & $\begin{array}{c}\text { Investimentos } \\
\text { ambientais } \\
\text { quantitativos - } \\
\text { ISE }\end{array}$ & $\begin{array}{c}\% \\
\text { Investimentos } \\
\text { ambientais } \\
\text { quantitativos - } \\
\text { ISE }\end{array}$ & $\begin{array}{c}\text { Investimentos } \\
\text { ambientais } \\
\text { quantitativos - } \\
\text { Não ISE }\end{array}$ & $\begin{array}{c}\% \\
\text { Investimentos } \\
\text { ambientais } \\
\text { quantitativos - } \\
\text { Não ISE }\end{array}$ & $\begin{array}{c}\text { Total } \\
\text { Investimentos } \\
\text { ambientais } \\
\text { quantitativos }\end{array}$ \\
\hline Bens industriais & 1 & 3,70 & 3 & 13,64 & 4 \\
\hline Construção e transporte & 3 & 11,11 & 5 & 22,73 & 8 \\
\hline Consumo cíclico & 1 & 3,70 & 0 & 0,00 & 1 \\
\hline Consumo não cíclico & 1 & 3,70 & 3 & 13,64 & 4 \\
\hline Financeiro e outros & 2 & 7,41 & 1 & 4,55 & 3 \\
\hline Materiais básicos & 6 & 22,22 & 2 & 9,09 & 8 \\
\hline $\begin{array}{l}\text { Petróleo, gás e } \\
\text { biocombustíveis } \\
\text { Tecnologia da }\end{array}$ & 0 & 0,00 & 2 & 9,09 & 2 \\
\hline informação & 0 & 0,00 & 0 & 0,00 & 0 \\
\hline Telecomunicações & 2 & 7,41 & 1 & 4,55 & 3 \\
\hline Utilidade pública & 11 & 40,74 & 5 & 22,73 & 16 \\
\hline Total & 27 & 100,00 & 22 & 100,00 & 49 \\
\hline
\end{tabular}

Nota. Fonte: Dados da Pesquisa (2015)

O setor que divulgou a maior média de investimentos ambientais quantitativos das empresas do ISE é o de Materiais Básicos, com R\$276.419.159,18, e o segundo setor que divulgou mais investimentos quantitativos (Tabela 12). Das empresas não pertencentes ao ISE o setor que apresenta a maior média é o de Petróleo, Gás e Biocombustíveis, pois somente a Petrobras compreende $\mathrm{R} \$ 3.276 .900 .000,00$ de investimentos ambientais o que faz com que a média das empresas que pertencem a esse setor seja alta.

Tabela 12

Média das empresas elegíveis que divulgaram investimentos ambientais quantitativos por setor

\begin{tabular}{ccc}
\hline Setor & $\begin{array}{c}\text { Média de Investimentos } \\
\text { ambientais quantitativos - } \\
\text { ISE }\end{array}$ & $\begin{array}{c}\text { Média de Investimentos } \\
\text { ambientais quantitativos - } \\
\text { Não ISE }\end{array}$ \\
\hline Bens industriais & $\mathrm{R} \$ 11.122 .000,00$ & $\mathrm{R} \$ 9.462 .166,40$ \\
Construção e transporte & $\mathrm{R} \$ 9.370 .968,85$ & $\mathrm{R} \$ 7.061 .896,80$ \\
Consumo cíclico & $\mathrm{R} \$ 647.664,00$ & $\mathrm{R} \$ 0,00$ \\
Consumo não cíclico & $\mathrm{R} \$ 208.410 .000,00$ & $\mathrm{R} \$ 15.070 .613,33$ \\
Financeiro e outros & $\mathrm{R} \$ 165.548 .500,00$ & $\mathrm{R} \$ 44.689 .000,00$ \\
Materiais básicos & $\mathrm{R} \$ 276.419 .159,18$ & $\mathrm{R} \$ 238.439 .525,00$ \\
Petróleo, gás e biocombustíveis & $\mathrm{R} \$ 0,00$ & $\mathrm{R} \$ 1.641 .339 .681,82$ \\
Tecnologia da informação & $\mathrm{R} \$ 0,00$ & $\mathrm{R} \$ 0,00$ \\
Telecomunicações & $\mathrm{R} \$ 8.730 .670,50$ & $\mathrm{R} \$ 8.094 .690,53$ \\
Utilidade pública & $\mathrm{R} \$ 96.117 .252,73$ & $\mathrm{R} \$ 101.897 .669,32$ \\
\hline Total & $\mathbf{R} \$ \mathbf{1 2 2 . 6 9 0 . 9 4 9 , 8 8}$ & $\mathbf{R} \$ \mathbf{2 0 1 . 3 9 7 . 1 9 4 , 2 7}$
\end{tabular}

Nota. Fonte: Dados da Pesquisa (2015).

$\mathrm{Na}$ Tabela 13 é possível verificar as estatísticas descritivas dos investimentos quantitativos das empresas elegíveis, considerando o $\mathrm{R} \$ 0,00$ como valor mínimo. A única 
empresa que possui relatório, mas não possui o investimento quantitativo considerando o $\mathrm{R} \$$ 0,00 é a Multiplus, pois a Tupy apesar de estar excluída da Tabela 9, por não mencionar os investimentos de forma qualitativa, divulgou os valores quantitativos.

Em relação aos investimentos quantitativos, as empresas do ISE, ao considerarem o $R \$$ 0,00 , apresentaram melhor média, apesar de o maior valor pertencer à Petrobras, empresa não pertencente ao ISE. O desvio padrão menor indica que os valores devem estar próximos à média, ao contrário das empresas não pertencentes ao ISE em que os dados estão mais dispersos da média.

Tabela 13

Investimentos quantitativos considerando o $\mathbf{R} \$ 0,00$ (R\$)

\begin{tabular}{cccccc}
\hline $\begin{array}{c}\text { Empresas } \\
\text { Elegíveis }\end{array}$ & $\begin{array}{c}\text { Quantidade de } \\
\text { empresas }\end{array}$ & Média & Máximo & Mínimo & Desvio padrão \\
\hline ISE & 40 & $\mathrm{R} \$ 82.816 .391,17$ & $\mathrm{R} \$ 864.800 .000,00$ & $\mathrm{R} \$ 0,00$ & $\mathrm{R} \$ 162.624 .927,11$ \\
$\mathrm{~N} \tilde{\mathrm{A}} \mathrm{ISE}$ & 54 & $\mathrm{R} \$ 82.050 .708,78$ & $\mathrm{R} \$ 3.276 .900 .000,00$ & $\mathrm{R} \$ 0,00$ & $\mathrm{R} \$ 451.114 .856,05$ \\
\hline Total & $\mathbf{9 4}$ & $\mathbf{R} \mathbf{8 2 . 3 7 6 . 5 3 1 , 0 7}$ & $\mathbf{R} \mathbf{3 . 2 7 6 . 9 0 0 . 0 0 0 , 0 0}$ & $\mathbf{R} \mathbf{0} \mathbf{0 0 0}$ & $\mathbf{R} \mathbf{3 5 6 . 4 6 3 . 9 0 2 , 6 1}$ \\
\hline
\end{tabular}

Nota. Fonte: Dados da Pesquisa (2015).

$\mathrm{Na}$ Tabela 14 são apresentados os investimentos quantitativos desconsiderando o $\mathrm{R} \$$ 0,00 como valor mínimo, pois o $\mathrm{R} \$ 0,00$ corresponde a empresas que mencionavam apenas investimentos ambientais de forma qualitativa sem citar os quantitativos. Ao desconsiderar o valor $\mathrm{R} \$ 0,00$, a média das empresas não pertencentes ao ISE torna-se maior, apesar de ter desvio padrão elevado indicando que algumas empresas apresentam investimentos ambientais que se distanciam da média. Excluindo a Petrobras, empresa que possui o maior investimento das empresas não pertencentes ao ISE, a média corresponde a $R \$ 54.944 .679,71$. Verifica-se que a média das empresas não pertencentes ao ISE é maior, pois a Petrobras detém um investimento muito significativo.

Tabela 14

Investimentos quantitativos desconsiderando o $\mathbf{R} \$ 0,00(\mathbf{R} \$)$

\begin{tabular}{cccccc}
\hline $\begin{array}{c}\text { Empresas } \\
\text { elegíveis }\end{array}$ & $\begin{array}{c}\text { Quantidade } \\
\text { de } \\
\text { empresas }\end{array}$ & Média & Máximo & Mínimo & Desvio padrão \\
\hline ISE & 27 & $\mathrm{R} \$ 122.690 .949,88$ & $\mathrm{R} \$ 864.800 .000,00$ & $\mathrm{R} \$ 548.800,00$ & $\mathrm{R} \$ 185.983 .573,28$ \\
$\mathrm{~N} \tilde{\mathrm{O}} \mathrm{ISE}$ & 22 & $\mathrm{R} \$ 201.397 .194,27$ & $\mathrm{R} \$ 3.276 .900 .000,00$ & $\mathrm{R} \$ 523.600,00$ & $\mathrm{R} \$ 698.874 .996,19$ \\
\hline Total & $\mathbf{4 9}$ & $\mathbf{R} \$ \mathbf{1 5 8 . 0 2 8 . 4 4 7 , 3 6}$ & $\mathbf{R} \$ \mathbf{3 . 2 7 6 . 9 0 0 . 0 0 0 , 0 0}$ & $\mathbf{R} \$ \mathbf{5 2 3 . 6 0 0 , 0 0}$ & $\mathbf{R} \$ \mathbf{4 8 3 . 7 2 2 . 1 8 2 , 6 7}$ \\
\hline
\end{tabular}

Nota. Fonte: Dados da Pesquisa (2015)

A rentabilidade do ativo indica o quanto a empresa obteve de lucro com relação ao seu ativo total. A Tabela 15 mostra a análise desse indicador em \% e indica melhores médias para as empresas do ISE com menor dispersão, pois o desvio padrão é menor.

Tabela 15

Análise da Rentabilidade do Ativo das empresas elegíveis (em \%)

\begin{tabular}{cccccc}
\hline Empresas Elegíveis & $\begin{array}{c}\text { Quantidade } \\
\text { de empresas }\end{array}$ & Média & Máximo & Mínimo & Desvio padrão \\
\hline ISE & 40 & 4,47 & 17,29 & $-3,81$ & 4,61 \\
NÃO ISE & 138 & 2,97 & 33,29 & $-27,85$ & 8,82 \\
\hline Total & $\mathbf{1 7 8}$ & $\mathbf{3 , 3 1}$ & $\mathbf{3 3 , 2 9}$ & $\mathbf{- 2 7 , 8 5}$ & $\mathbf{8 , 0 8}$ \\
\hline
\end{tabular}

Nota. Fonte: Dados da Pesquisa (2015)

A Tabela 16 apresenta a análise do grau de endividamento em \% e apesar do valor máximo ser de empresas não pertencentes ao ISE, as empresas do ISE possuem maior grau de endividamento do que aquelas. Pela análise desse indicador percebe-se que as empresas não pertencentes ao ISE estão menos endividadas. Mesmo excluindo-se a empresa que possui o valor máximo (IBG S.A.), a média corresponde a 58,96\%, abaixo das empresas do ISE. 
Tabela 16

Análise do grau de endividamento das empresas elegíveis (em \%)

\begin{tabular}{cccccc}
\hline Empresas Elegíveis & $\begin{array}{c}\text { Quantidade de } \\
\text { empresas }\end{array}$ & Média & Máximo & Mínimo & Desvio padrão \\
\hline ISE & 40 & 65,29 & 94,40 & 13,10 & 17,96 \\
NÃO ISE & 138 & 57,96 & 173,80 & 12,50 & 23,88 \\
\hline Total & $\mathbf{1 7 8}$ & $\mathbf{5 9 , 6 1}$ & $\mathbf{1 7 3 , 8 0}$ & $\mathbf{1 2 , 5 0}$ & $\mathbf{2 2 , 8 4}$ \\
\hline
\end{tabular}

Nota. Fonte: Dados da Pesquisa (2015).

A análise do índice de liquidez corrente das empresas elegíveis é demonstrada na Tabela 17, em as empresas não integrantes da carteira ISE apresentaram melhor média se comparadas com as demais, apesar de possuírem maior desvio padrão. A BBseguridade foi a única empresa que não mencionou o valor do indicador de liquidez corrente.

Tabela 17

Análise da liquidez corrente das empresas elegíveis

\begin{tabular}{cccccc}
\hline Empresas Elegíveis & $\begin{array}{c}\text { Quantidade de } \\
\text { empresas }\end{array}$ & Média & Máximo & Mínimo & Desvio padrão \\
\hline ISE & 40 & 1,53 & 3,80 & 0,60 & 0,74 \\
NÃO ISE & 137 & 1,82 & 12,10 & 0,00 & 1,31 \\
\hline Total & $\mathbf{1 7 7}$ & $\mathbf{1 , 7 5}$ & $\mathbf{1 2 , 1 0}$ & $\mathbf{0 , 0 0}$ & $\mathbf{1 , 2 1}$ \\
\hline
\end{tabular}

Nota. Fonte: Dados da Pesquisa (2015).

Excluiu-se a Qgep Part da amostra para testar novamente as médias e analisar se era somente essa empresa que estava distante, uma vez que representava 12,1. Porém, apesar de a média cair para 1,75 , não foi o suficiente para as empresas do ISE apresentarem melhor desempenho.

Também foi analisado o ativo total e observou-se que a média das empresas ISE é superior em relação às não ISE, porém o desvio padrão também é maior, demonstrando maior dispersão dos dados. Por meio da análise percebe-se que as empresas ISE são de maior porte, pois estão bem acima da média do total de empresas elegíveis (Tabela 18).

Tabela 18

Análise do Ativo Total das empresas elegíveis (em milhares de reais)

\begin{tabular}{cccccc}
\hline Empresas Elegíveis & $\begin{array}{c}\text { Quantidade } \\
\text { de empresas }\end{array}$ & Média & Máximo & Mínimo & Desvio padrão \\
\hline ISE & 40 & $137.481 .045,48$ & $1.437 .485 .512,00$ & $3.209 .768,00$ & $333.213 .263,38$ \\
NÃO ISE & 138 & $14.692 .070,10$ & $793.375 .000,00$ & $70.155,00$ & $68.406 .424,95$ \\
\hline Total & $\mathbf{1 7 8}$ & $\mathbf{4 2 . 2 8 5 . 0 9 8 , 2 8}$ & $\mathbf{1 . 4 3 7 . 4 8 5 . 5 1 2 , 0 0}$ & $\mathbf{7 0 . 1 5 5 , 0 0}$ & $\mathbf{1 7 5 . 2 9 4 . 0 3 4 , 3 2}$ \\
\hline
\end{tabular}

Nota. Fonte: Dados da Pesquisa (2015).

Por meio da análise de regressão logística verificou-se fatores que interferem na seleção de empresas para compor o ISE. A amostra foi composta por 177 empresas elegíveis. A BBseguridade foi excluída por não apresentar o indicador de liquidez. Consideraram-se as seguintes opções: Diagramas de classificação; Qualidade do ajuste de Hosmer-Lemeshow; $\mathrm{Cl}$ para $\exp (\mathrm{B})$ : 95\%; Probabilidade Por etapa: Entrada: 0,05 e Remoção: 0,10; Limite de classificação: 0,5; Máximo de interações: 20; Incluir constante no modelo. Analisaram-se as probabilidades e associação de grupo como valores previstos, incluindo a matriz de covariância. O método considerado foi o inserir, "que executa o modelo com todas as variáveis selecionadas pelo pesquisador" (Fávero et al., 2009, p. 447).

A variável dependente foi o ISE que considerava 1 para as empresas integrantes e 0 para as não pertencentes. As covariáveis analisadas foram: Logaritmo natural do ativo total (TAM), rentabilidade do ativo (ROA), liquidez corrente (LIQC), grau de endividamento (GEND), novo mercado (NM), investimentos ambientais qualitativos (INVQUALI) e investimentos ambientais quantitativos (INVQUANT).

Para as variáveis INVQUALI, INVQUANT e NM, assim como a variável dependente ISE, utilizaram-se variáveis dummies que indicam a presença ou ausência de um determinado atributo, assumindo apenas o valor 1 ou 0 (Corrar, Paulo, \& Dias, 2007). Ou seja, para 
INVQUANT foi considerado se a empresa evidenciava investimento ambiental quantitativo monetário, assumindo o valor 1 , ou não, representado pelo 0.

Testou-se o modelo eliminando INVQUALI e INVQUANTI incluindo investimento ambiental quantitativo (VALORINV), mas a análise não foi significante para qualquer variável. Não foi identificada alta correlação, possibilitando concluir que as variáveis explicativas não estão influenciando as demais. A Tabela 19 demonstra por meio do Qui-Quadrado que os coeficientes em conjunto são significativos. Foi testado se ao menos um dos coeficientes é diferente de 0 . Por meio do Sig $=0,000$, pelo menos uma das variáveis tem coeficiente diferente de 0 , rejeitando a hipótese de que os parâmetros são nulos. O modelo é válido ao nível de significância de 5\%.

Tabela 19

Teste Omnibus de coeficientes do modelo

\begin{tabular}{llccc}
\hline & & Chi-square & df & Sig. \\
\hline \multirow{2}{*}{ Step 1 } & Step & 92,000 & 7 &, 000 \\
& Block & 92,000 & 7 &, 000 \\
& Model & 92,000 & 7 &, 000 \\
\hline
\end{tabular}

Nota. Fonte: Dados da Pesquisa (2015).

O modelo proposto apresenta $61,7 \%$ de poder explicativo (Nagelkerke R Square), ou seja, as variáveis explicam $61,7 \%$ da aceitação das empresas ao ISE. Já o teste de HosmerLemeshow verifica a hipótese nula de que não há significativas diferenças entre as frequências previstas e observadas. O resultado indica que não há diferenças significativas entre as frequências previstas e observadas ao nível de significância, tendo em vista que o valor de Sig foi de 0,711 , não rejeitando a hipótese nula.

A Tabela 20 mostra se o modelo classifica corretamente os eventos, com base no ponto de corte c estabelecido inicialmente (Fávero et al., 2009). Em função da BBseguridade ter sido excluída por não mencionar a liquidez corrente, foram observadas 177 empresas. Pode-se concluir que há $88,7 \%$ de acerto da empresa pertencer ou não ao ISE. As empresas não pertencentes ao ISE são classificadas corretamente em $94,9 \%(130 /(130+7))$ e as não ISE em $67,5 \%(27 /(27+13))$.

Tabela 20

Tabela de classificação

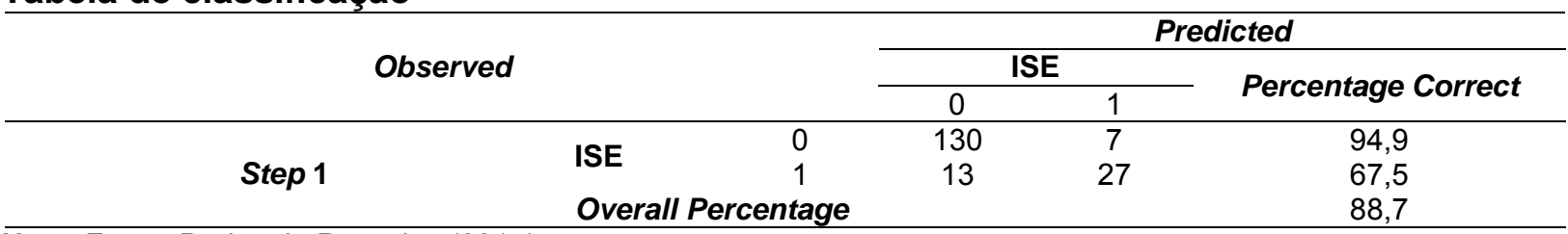

Nota. Fonte: Dados da Pesquisa (2015).

A Tabela 21 indica as variáveis, apresentando os resultados que são significativos na seleção de empresas para compor o ISE. Foi possível concluir que as variáveis significativas eram: TAM, ROA, GEND e INVQUANT (tamanho, rentabilidade do ativo, grau de endividamento e investimento ambiental quantitativo), as quais interferem na seleção de empresas para compor o ISE. Já liquidez corrente, investimento ambiental qualitativo e pertencer ao Novo Mercado não mostraram significância com relação à empresa fazer parte ou não do ISE. A variável TAM foi significativa ao nível de 1\%, já GEND e INVQUANT ao nível de $5 \%$ e ROA ao nível de $10 \%$. 
Tabela 21

Variáveis na equação

\begin{tabular}{|c|c|c|c|c|c|c|c|c|c|}
\hline & & \multirow{2}{*}{ B } & \multirow{2}{*}{ S.E. } & \multirow{2}{*}{ Wald } & \multirow{2}{*}{ df } & \multirow{2}{*}{ Sig. } & \multirow{2}{*}{$\operatorname{Exp}(B)$} & \multicolumn{2}{|c|}{ 95\% C.I.for EXP(B) } \\
\hline & & & & & & & & Lower & Upper \\
\hline \multirow{8}{*}{ Step 1} & TAM & 0,758 & 0,243 & 9,745 & 1 & 0,002 & 2,135 & 1,326 & 3,437 \\
\hline & ROA & 0,1 & 0,052 & 3,658 & 1 & 0,056 & 1,105 & 0,998 & 1,224 \\
\hline & LIQC & $-0,012$ & 0,254 & 0,002 & 1 & 0,961 & 0,988 & 0,601 & 1,624 \\
\hline & GEND & 0,032 & 0,016 & 3,853 & 1 & 0,05 & 1,032 & 1 & 1,065 \\
\hline & $N M(1)$ & $-0,47$ & 0,53 & 0,786 & 1 & 0,375 & 0,625 & 0,221 & 1,766 \\
\hline & INVQUALI(1) & $-19,629$ & 4048,87 & 0 & 1 & 0,996 & 0 & 0 & . \\
\hline & INVQUANT(1) & $-1,062$ & 0,506 & 4,405 & 1 & 0,036 & 0,346 & 0,128 & 0,932 \\
\hline & Constant & $-14,375$ & 4,375 & 10,795 & 1 & 0,001 & 0 & & \\
\hline
\end{tabular}

Nota. Fonte: Dados da Pesquisa (2015).

O estudo detectou que a análise dos índices está em consonância com a análise da regressão logística ao identificar que o tamanho, a rentabilidade do ativo, o grau de endividamento e o investimento ambiental quantitativo foram os fatores que influenciaram na seleção de empresas para compor o ISE, possibilitando chegar à mesma conclusão.

\section{CONCLUSÕES}

Para atingir o objetivo da pesquisa foi identificado, inicialmente, se as empresas divulgaram investimentos ambientais em seus relatórios de sustentabilidade. Das 178 empresas elegíveis analisadas, 95 apresentaram relatórios. 93 companhias relatam que investiram em aspectos ambientais e 49 mencionam valores monetários.

Além disso, comparou-se se empresas do ISE possuem maiores investimentos ambientais do que empresas não pertencentes ao ISE. Para as empresas que divulgaram relatórios, $100 \%$ das companhias do ISE apresentaram investimentos ambientais de forma qualitativa e $67,5 \%$ os quantitativos, correspondendo a uma maior proporção de investimentos as empresas integrantes do ISE, pois das empresas não pertencentes ao ISE apenas $40 \%$ divulgaram valores quantitativos e $96,36 \%$ de forma qualitativa.

Ao se calcular os indicadores econômico-financeiros e analisar as estatísticas descritivas, concluiu-se que o ativo total, rentabilidade do ativo e grau de endividamento apresentaram as maiores médias para empresas integrantes do ISE. E, por meio da regressão logística, avaliou-se se alguns fatores influenciaram na seleção das empresas para compor o ISE. Verificou-se que TAM, ROA, GEND e INVQUANT interferiram na seleção das companhias ao ISE. A análise dos índices está em conformidade com a regressão logística obtendo a mesma conclusão. As variáveis TAM, ROA, GEND e INVQUANT influenciaram a seleção das empresas para compor o ISE, mas LIQC, INVQUALI e NM não mostraram resultados significativos. A variável TAM foi significante ao nível de $1 \%$, GEND e INVQUANT ao nível de $5 \%$ e ROA ao nível de $10 \%$.

Devido aos critérios utilizados, não se pode generalizar o resultado, pois, se forem considerados outros parâmetros, poderão ser obtidas conclusões diferentes. Outra limitação da pesquisa é que se refere a um único período (2014). Não foi aplicado a outras épocas. Além disso, nem todas as empresas divulgaram relatórios de sustentabilidade. Assim, para trabalhos futuros, recomenda-se a verificação de mais períodos de tempo e a análise do aspecto social, envolvendo investimentos socioambientais. Propõe-se também considerar a economia de recursos decorrentes de investimentos socioambientais e fazer novas seleções, como por exemplo, as companhias mais rentáveis.

\section{REFERÊNCIAS}

Azevedo, A. L. V. (2006). Indicadores de sustentabilidade empresarial no Brasil: uma avaliação do Relatório do CEBDS. Revista Iberoamericana de Economía Ecológica, [s.i], 5, 75-93. Recuperado em 03 agosto, 2015, de http://www.redibec.org/IVO/rev5_06.pdf 
Barbieri, J. C. (2011). Gestão ambiental empresarial: conceitos, modelos e instrumentos (3a ed.). São Paulo: Saraiva.

Barbieri, J. C., \& Cajazeira, J. E. R. (2009). Responsabilidade Social Empresarial e Empresa Sustentável: Da teoria à prática. São Paulo: Saraiva.

Bertagnolli, D. D. O., Ott, E., \& Damacena, C. (2006, julho). Estudo sobre a Influência dos Investimentos Sociais e Ambientais no Desempenho Econômico das Empresas. Anais do VI Congresso USP de Controladoria e Contabilidade, São Paulo, FEA/USP. Recuperado em 20 agosto, 2015, de www.congressousp.fipecafi.org/web/artigos62006/548.pdf

Beuren, I. M. (2006). Como Elaborar Trabalhos Monográficos em Contabilidade: Teoria e prática (3a ed.). São Paulo: Atlas.

BMF\&Bovespa - Bolsa de Valores, Mercadorias e Futuros de São Paulo. Índice de Sustentabilidade Empresarial - ISE. Recuperado em 24 agosto, 2015 de http://www.bmfbovespa.com.br/indices/Resumolndice.aspx? Indice=ISE\&Idioma=pt-br

BMF\&Bovespa - Bolsa de Valores, Mercadorias e Futuros de São Paulo. Novo Mercado. Recuperado em 23 outubro, 2015 de http://www.bmfbovespa.com.br/pt$\mathrm{br} / \mathrm{servicos} /$ solucoes-para-empresas/segmentos-de-listagem/novo-mercado.aspx?idioma $=p t-b r$

Bronstein, C. GRI - Global Reporting Initiative. Recuperado em 01 dezembro, 2015 de http://www.bmfbovespa.com.br/pt-br/a-bmfbovespa/download/Como-publicar-relatorio-desustentabilidade.pdf

Comissão Mundial Sobre o Meio Ambiente e Desenvolvimento (1991). Nosso futuro comum: relatório Brundtland: 1897 (2a ed.). Rio de Janeiro: FGV.

Corrar, L. J., Paulo, E., \& Dias, J. M., Filho, (2007). Análise Multivariada: para os cursos de Administração, Ciências Contábeis e Economia. São Paulo: Atlas.

Dalmácio, F. Z., \& Paulo, F. F. M. (2004) A evidenciação contábil: publicação de aspectos sócio-ambientais e econômico-financeiros nas demonstrações contábeis. Anais do IV Congresso USP de Controladoria e Contabilidade, São Paulo, FEA/USP. Recuperado em $18 \quad$ agosto, 2015 de http://www.fucape.br/_public/producao_cientifica/2/Dalm\%C3\%A1cio,Flavia\%20Z\%C3\%B 3boli.\%20A\%20evidencia\%C3\%A7\%C3\%A30\%20cont\%C3\%A1bil.pdf

Dias, R. Responsabilidade Social: Fundamentos e Gestão (2012). São Paulo: Atlas.

Favaro, L. C., \& Rover, S. (2014). Índice de Sustentabilidade Empresarial (ISE): a associação entre os indicadores econômico-financeiros e as empresas que compõem a carteira. CONTABILOMETRIA - Brazilian Journal of Quantitative Methods Applied to Accounting, Monte Carmelo, 1(1), 39-55. Recuperado em 29 outubro, 2015 de http://www.fucamp.edu.br/editora/index.php/contabilometria/article/download/440/318

Fávero, L.P., Belfiore, P., Silva, F.L., \& Chan, B.L. (2009). Análise de dados: modelagem multivariada para a tomada de decisões. Rio de Janeiro: Campus.

França, L. M. (2004). Indicadores De Produção Limpa: Uma Proposta Para Análise De Relatórios Ambientais De Empresas. Dissertação de Mestrado, Curso de Gerenciamento e Tecnologia Ambiental no Processo Produtivo, Universidade Federal da Bahia, Salvador, Baha, Brasil. Recuperado em 03 agosto, 2015 de http://www.teclim.ufba.br/site/material_online/dissertacoes/dis_ligia_m_f_cardoso.pdf

Garcia, A. S., \& Orsato, R. J. (2013, setembro). Índices de sustentabilidade empresarial porque participar? Anais do Encontro Nacional da Associação Nacional de Pós-Graduação e Pesquisa em Administração, Rio de Janeiro, RJ. Recuperado em 23 agosto, 2015 de http://www.anpad.org.br/admin/pdf/2013_EnANPAD_ESO1759.pdf 
Global Reporting Initiative. Relatórios de Sustentabilidade da GRI: Quanto vale essa jornada?. 2012. Recuperado em 01 dezembro, 2015 de https://www.globalreporting.org/resourcelibrary/Portuquese-Starting-Points-2-G3.1.pdf

Global Reporting Initiative. Princípios para relato e conteúdos padrão, 2013. Recuperado em 01 dezembro, 2015 de http://www.bmfbovespa.com.br/pt-br/a-bmfbovespa/download/GRIG4-Principios-para-Relato-e-Conteudos-Padrao.pdf

Global Reporting Initiative. About GRI, 2016. Recuperado em 13 setembro, 2016 de https://www.globalreporting.org/information/about-gri/Pages/default.aspx

Guimarães, C. C. (2010). Impacto do ISE no valor de empresa obtido pelo modelo ohlson. Dissertação de Mestrado, Curso de Ciências Contábeis, Fecap, São Paulo, SP, Brasil. $\begin{array}{lllll}\text { Recuperado em } & 20 & \text { agosto, } & 2015\end{array}$ http://200.169.97.106/biblioteca/tede//tde_busca/arquivo.php?codArquivo=230

Índice de Sustentabilidade Empresarial. O que é o ISE. Recuperado em 01 dezembro, 2015 de http://www.isebvmf.com.br/index.php?r=site/conteudo\&id=1

Loesch, C. (2012). Probabilidade e Estatística. Rio de Janeiro: LTC.

Macedo, M. A. S., Souza, A. C., Souza, A. C. C., \& Cipola, F. C. (2007). Desempenho de empresas socialmente responsáveis: uma análise por índices contábilfinanceiros. Revista Produção Online, Florianópolis, Edição especial, 1-22. Recuperado em 03 agosto, 2015 de http://producaoonline.org.br/rpo/article/view/59/59

Machado, M. A. V., Macedo, M. A. S., Machado, M. R., \& Siqueira, J. R. M. (2012). Análise da relação entre investimentos socioambientais e a inclusão de empresas no Índice de Sustentabilidade Empresarial - (ISE) da BM\&FBovespa. R. Ci. Adm., [s.I.], 14(32),141156, 27 Recuperado em 21 julho, 2015 de https://periodicos.ufsc.br/index.php/adm/article/view/2175-8077.2012v14n32p141

Marcondes, A. W., \& Bacarji, C. D. (2010). ISE sustentabilidade no mercado de capitais. Recuperado em $21 \quad$ julho, 2015 de http://www.bmfbovespa.com.br/Indices/download/Livro-ISE.pdf

Nunes, T. C. S. (2010). Indicadores contábeis como medidas de risco e retorno diferenciados de empresas sustentáveis: um estudo no mercado brasileiro. Dissertação de Mestrado Curso de Ciências Contábeis, Departamento de Contabilidade e Atuária, Universidade de São Paulo, SP, Brasil. Recuperado em 20 agosto, 2015 de www.teses.usp.br/teses/disponiveis/12/12136/tde-04112010-190443

Nunes, J. G., Teixeira, A. J. C., Nossa, V., \& Galdi, F. C. (2010). Análise das variáveis que influenciam a adesão das empresas ao índice BM\&FBovespa de sustentabilidade empresarial. Base - Revista de Administração e Contabilidade da Unisinos, 7(4), 328-340. $\begin{array}{llll}\text { Recuperado em } & 20 & \text { agosto, } & 2015\end{array}$ revistas.unisinos.br/index.php/base/article/view/4609/1833

Ott, E.; Alves, T. W., \& Flores, G. S. S. (2009). Investimentos ambientais e o desempenho econômico das empresas: um estudo dos dados em painel. Anais do Encontro Anual da Associação Nacional dos Programas de Pós-graduação em Administração, São Paulo: Recuperado em 17 agosto, 2015 de http://www.anpad.org.br/admin/pdf/CON2307.pdf.

Pereira, A.C., Silva, G. Z., \& Carbonari, M. E.E. (2011). Sustentabilidade, responsabilidade social e meio ambiente. São Paulo: Saraiva.

Teixeira, E. A., Nossa, V., \& Funchal, B. (2011). O índice de sustentabilidade empresarial (ISE) e os impactos no endividamento e na percepção de risco. Revista Contabilidade \& Finanças, [s.I.], 22(55), 29-44. FapUNIFESP (SciELO). DOI: 10.1590/s151970772011000100003. Recuperado em 03 agosto, 2015 de http://www.scielo.br/pdf/rcf/v22n55/a03v22n55.pdf 
Tachizawa, T. (2015). Gestão ambiental e responsabilidade social corporativa: estratégias de negócios focadas na realidade brasileira (8a ed.). São Paulo: Atlas.

Tinoco, J. E. P., \& Kraemer, M.E.P. (2011). Contabilidade e gestão ambiental (3a ed.). São Paulo: Atlas.

Vellani, C. L. (2011). Contabilidade e responsabilidade social: integrando desempenho econômico, social e ecológico. São Paulo: Atlas. 